\title{
OPINIONS ON THE TAX DEDUCTIBILITY OF MORTGAGES AND THE CONSENSUS EFFECT*
}

\author{
BY \\ ELINE VAN DER HEIJDEN ${ }^{* *}$, JAN NELISSEN*** AND JAN POTTERS ${ }^{* *}$
}

\begin{abstract}
Summary
We present the results of a survey-experiment - using a representative sample of the Dutch population - in which we relate respondents' opinion about a restriction of the tax deductibility of mortgages to their estimates about other people's opinions. We find a strong consensus effect; meaning that respondents' estimates of others' opinions are related to their own opinion. Furthermore, we find that the size of the effect is not affected by the ambiguity of the question posed. The provision of arguments pro and contra the tax provision and monetary incentives for accuracy reduce the consensus effect, but only so in conjunction. Finally, we find that house owners display a significantly stronger consensus effect. Our results suggest that both cognitive and motivational factors are responsible for the consensus effect. Aside from the consensus effect, our survey gives interesting insights into people's opinion on tax deductibility of mortgages. A majority consider a general restriction to be unfair, but a proposal to restrict only mortgages as of a certain size meets with much more approval.
\end{abstract}

Key words: consensus effect, experiment, survey, taxation

JEL Code(s): C8, C9, D8, H2

\section{INTRODUCTION}

From the social psychological literature it is known that expectations about others are positively correlated with one's own behavioural inclinations. This is called the consensus effect (or social projection). It refers to the tendency of individuals to see their own preferences and beliefs as relatively common while viewing alternative preferences and beliefs as relatively uncommon (Ross et al. (1977)). The consensus effect may thus be seen as a type of

* We thank Marcel Das and Corrie Vis of CentERdata for their excellent support in conducting the survey-experiment and two referees of this journal and Dirk Engelmann for helpful comments. Financial support from the Faculty of Economics and Business administration is gratefully acknowledged.

** CentER \& Department of Economics, Tilburg University, P.O. Box 90153, 5000 LE Tilburg, The Netherlands, phone: +31-13-466.8204, fax: +31-13-466.3042, emails: eline.vanderheijden@ uvt.nl; j.j.m.potters@uvt.nl

*** CentERdata, Tilburg University, P.O. Box 90153, 5000 LE Tilburg, The Netherlands, email: j.h.m.nelissen@uvt.nl 
egocentric bias, in the sense that people overweight their own opinion when estimating the opinions of others. ${ }^{1}$

The existence of a consensus effect is of great importance for economics. In many economic settings, agents must form expectations about the preferences and beliefs of others in order to make good decisions. In assets markets, for example, optimal trading strategies rely on one's expectations about how other traders believe the market will develop. The optimal bid in an auction depends on one's expectation about other bidders' valuation of the object for sale. The decision to market a new product will depend on one's expectation about the preferences of consumers. It is easy to give other examples of economic environments in which expectations about others are crucial to decision-making.

A standard and crucial assumption in economics is that people have rational expectations about the preferences, beliefs, and behaviour of others. This implies that expectations are correct on average and contain no systematic (i.e., correctible) biases. However, if people are affected by a consensus effect this implies that economic decision-making may contain systematic mistakes and lead to inefficient outcomes. If traders, for example, overestimate the extent to which their own opinions are representative for those of other traders, asset prices may be biased (Forsythe et al. (1992)). If bidders with a high valuation take their own valuation as representative for those of others, this may lead to overbidding in auctions. If people take their own tastes as representative for those of others, this may lead to a high failure rate of small businesses (Camerer (1995)).

In the social psychological literature there are many documented manifestations of the consensus effect. One can think of candidate preference (Brown (1982)), approval for the performance of politicians (Goethals et al. (1979)), agreement on specific policy decisions (for example boycotting the Olympics) and consent for political movements (Manstead (1982)). In the economics literature the evidence is still somewhat mixed, however. On the one hand, Offerman et al. (1996) looked at individual orientations and expectations about the behaviour of other subjects in a step-level public good experiment, using incentive compatible mechanisms. They found that persons with a cooperative orientation contributed more than individualists did, but that cooperators did not expect more contributions by others than individualists did. Expectations were not affected systematically by own orientation. Selten and

1 In the psychological literature there seems to be little doubt that the consensus effect is a judgment bias. Therefore, it is often called the false consensus effect. The argument is that if both sides on an issue regard their own preference as relatively common at least one side must be wrong. But as Dawes (1990) put forward this is not necessarily the case. One's own preference is an informative signal about the population distribution of preferences. Oneself is a sample of size one, and if the prior belief about the underlying population distribution is rather imprecise, it is rational to update this prior into the direction of one's own preference. 
Ockenfels (1998), on the other hand, reported the presence of a consensus effect in the analysis of expectations about the gifts of others in a threeperson-gift game. Those with relatively large gifts also expected relatively large gifts by others. Similar results have been found by Brosig et al. (2003), Charness and Grosskopf (2001), and Jacobsen and Sadrieh (1996).

A clever experiment by Engelmann and Strobel (2000) was explicitly designed to examine whether the consensus effect is false. In each session 16 subjects had to make a choice between two options. After that a subject received information about the choices made by four other subjects in the session. Then each subject was asked to predict the choices of the remaining 11 subjects. The results indicate that subjects did use their own choice when forming an estimate about the choices of the other 11 subjects, but that they did not weight their own choice more heavily than the choices of the other 4 subjects they were informed about. In other words, the authors found a consensus effect but no false consensus effect. ${ }^{2}$ A follow-up study by Engelmann and Strobel (2004) showed, however, that the false consensus effect was destroyed only if representative information about others was presented to subjects on a 'silver platter' (like in their earlier study). If a small cognitive effort was required to retrieve the information then it tended to be ignored and the false consensus effect reappeared.

Several explanations for the consensus effect have been advanced. These explanations rely on motivational and cognitive factors (Marks and Miller (1987), Mullen and $\mathrm{Hu}$ (1988)). Motivational explanations emphasize the functional value of a person's position relative to the position of others. Similarity between self and others may serve to validate the appropriateness of a person's position, to maintain self-esteem, and to reduce tension in anticipated social interaction. It makes people feel better if they perceive and report similarity between their own position and that of others. Cognitive explanations, on the other hand, refer to the reasoning and informational processes that underlie the reported position of others on an issue. Here, two channels may bring about a correlation between a person's own position and the perceived position of others. One is what may be called selective exposure or availability. To form an estimate of the positions of others in general it is reasonable to rely, at least in part, on the positions one knows that some people have, including one's own position (a sample). To the extent that this sample is biased, it may bring about a consensus effect between one's own position and the position of others. A second cognitive channel is what is called object construal. Issues and questions are usually ambiguous to some degree and open to interpretation. The particular interpretation a person gives to an issue may affect one's own position as well as the estimated position of others.

2 We note that our study is not directly oriented towards the question whether the consensus effect is truly false. 
Insofar as interpretations differ across individuals they may lead to correlations between own position and perceived position of others.

In this paper we investigate the causes of a consensus bias. To that end we performed a survey-experiment using a representative sample of about 1500 Dutch households. We asked the respondents for their opinion on a proposed policy change regarding the tax deductibility of the interest on mortgages. This deductibility has been under serious attack in the Netherlands for some time. We also asked respondents to estimate the average response to this question in the panel. This allows us to assess the strength of the consensus effect by relating respondents' own opinions to their estimates of the average opinion.

Our contribution is threefold. First, we examine whether and how the relationship between own and estimated opinions is affected by three treatment variables. Firstly, we vary the ambiguity of the question posed. Secondly, we vary whether or not respondents are provided with a list of arguments pro and contra the proposed policy change. Finally, we examine whether the provision of monetary incentives for accuracy affects the consensus effect. Each of these treatments is targeted at one of the three explanations discussed above: object construal, selective exposure, and motivation, respectively.

Our second goal is to relate the consensus effect to various socio-demographic background variables of the respondents, of which especially house ownership seems relevant. As maintaining mortgage deductibility is obviously much more important for house owners than for tenants, we can, for instance, test the argument that the strength of a (false) consensus effect depends on the importance of the topic under consideration (Crano (1983), Campbell (1986), Marks and Miller (1987)).

Third, our study tries to provide insights in people's opinions about the tax deductibility of mortgages. As said, this is a tricky policy issue in the Netherlands and for quite some time it seemed that politicians were not willing to burn their fingers on the issue. Interestingly, however, a fierce discussion about a possible restriction has started again recently. Our results might give some useful insights about people's opinions on the issue and whether this varies with the type of restriction proposed. Also we can relate opinions to political orientation, house ownership and other socio-economic variables. This may give a better view on the possible political (electoral) consequences of a particular policy position.

The remainder of the paper reads as follows. Section 2 describes the experimental design and hypotheses. Section 3 starts with a detailed examination of people's opinions on the tax deductibility. Section 4 then analyzes the consensus effect. Section 5 discusses the accuracy of the estimates, and examines the effect of monetary incentives more closely. Section 6 concludes. 


\section{EXPERIMENTAL DESIGN AND HYPOTHESES}

For the survey-experiment we used the members of the CentERpanel, a largescale panel, set-up and maintained by CentERdata, which is a survey research institute, specialized in Internet-based surveys, affiliated with Tilburg University in the Netherlands. The panel consists of some 2000 households in the Netherlands, whose members fill in a questionnaire on the Internet at home every week. The panel is representative of the Dutch population with respect to age, gender, household size, level of education, religion, and region, albeit that young persons and immigrants are somewhat underrepresented. The survey was conducted in week 50 of the year 2001. A total of 1761 panel members decided to participate, which led to 1454 usable responses (i.e., valid responses for the main questions; see below).

The topic considered was the tax deductibility of mortgages. Currently, people can deduct the total amount of interest they pay for their mortgage from their taxable income. The tax provision is thus particularly beneficial for people with a high mortgage and a high marginal income tax rate. There have been several proposals to restrict the tax deductibility of mortgage interest payments. One proposal, by the Socialist Party (SP), is to set an upper limit of about 180000 Euro on the part of the mortgage with a tax-deductible interest payment.

We employed three treatment variables in the survey-experiment, in a $2 \times$ $2 \times 2$ factorial design in which respondents were randomly assigned to one of eight treatments. Table 1 gives an overview of the treatments and the number of respondents per treatment. The first treatment variable refers to the specificity of the question posed. One set of respondents was confronted with a general and ambiguous policy proposal (Ambiguous). They were asked Question A1: 'Do you consider a restriction of the mortgage interest deductibility to be fair? Give your opinion in the form of a grade on a scale from 1 (very unfair) to 10 (very fair)'. ${ }^{3}$ The other respondents were presented with a more specific proposal (Specific), Question A2: 'Do you consider a restriction of the mortgage interest deductibility for mortgages above 180000 Euro to be fair? Give your opinion in the form of a grade on a scale from 1 (very unfair) to 10 (very fair)'.

The second treatment variable determines whether or not respondents were confronted with a set of arguments concerning the policy proposal after they had given their own opinion but before they were asked to assess the opinion of others. Only in the treatment with this information (Arguments), we posed question B: 'Below you find six arguments concerning the mortgage interest deductibility. Could you assign a total of 100 points to these arguments?

3 The full text of the complete set of questions is available from the authors upon request. 
TABLE 1 - OVERVIEW OF THE TREATMENTS

\begin{tabular}{llllll}
\hline Treatment & Scenario & Arguments & Paid & Question order & \# Usable responses \\
\hline 1 & Ambiguous & No & No & A1, C1 & 271 \\
2 & Ambiguous & Yes & No & A1, B, C1 & 92 \\
3 & Ambiguous & No & Yes & A1, C2 & 278 \\
4 & Ambiguous & Yes & Yes & A1, B, C2 & 119 \\
5 & Specific & No & No & A2, C1 & 194 \\
6 & Specific & Yes & No & A2, B, C1 & 142 \\
7 & Specific & No & Yes & A2, C2 & 261 \\
8 & Specific & Yes & Yes & A2, B, C2 & 97 \\
\hline
\end{tabular}

Please assign more points to the argument you consider more relevant, and fewer points to the argument you consider less relevant'. ${ }^{4}$

The third treatment variable relates to the incentive to provide an accurate estimate of others' opinion. In one treatment (Not paid), respondents did not receive monetary incentives. They were asked Question C1: 'What do you think the average answer (grade) is by the members of the panel to the question whether a restriction of the mortgage interest deductibility is fair?'. In the other treatment (Paid), the respondents were in a contest for a prize of 100 Euro to report an accurate estimate. They were asked Question C2: 'What do you think the average answer (grade) is by the members of the panel to the question whether a restriction of the mortgage interest deductibility is fair? If out of 100 respondents you are the one who estimates this grade best you earn 100 Euro'. In all treatments this question $(\mathrm{C} 1$ or $\mathrm{C} 2)$ was asked after the opinion question, such that paying subjects for their estimates or not should not influence one's opinion.

Depending on the causes of the consensus effect, we expect to find different effects of the three treatment variables. First consider object construal, which suggests that questions with wider latitude of interpretation will show a stronger consensus effect than questions permitting only a more narrow interpretation. In our study the policy proposal in which a specific upper limit on the size of the mortgage is mentioned (Specific) is expected to be less open to interpretation than the more general proposal (Ambiguous). In particular, the Specific scenario hints much more directly at the (unfair) redistributional consequences of the mortgage deductibility. This gives our first hypothesis:

4 Two of the six arguments were in favour of the proposed policy change (e.g., people with high income benefit more from full deductibility than people with low income), two argued against a change (e.g., a restriction leads to financial problems of house owners), and two arguments were neutral (e.g., tax deductibility varies across countries). 


\section{Hypothesis 1.}

$\mathrm{H}_{0}$ : Specificity does not affect the consensus effect.

$\mathrm{H}_{1}$ : Specificity weakens the consensus effect.

The second hypothesis concerns the effect of monetary incentives. If the consensus effect is related to motivational mechanisms such as self-esteem maintenance and need for social support, one can argue that the relative importance of these motivations is reduced (crowded out) by payment. Being right may be a substitute motive for being similar if accuracy is rewarded. This yields the following hypothesis:

\section{Hypothesis 2.}

$\mathrm{H}_{0}$ : Monetary incentives do not affect the consensus effect.

$\mathrm{H}_{1}$ : Monetary incentives weaken the consensus effect.

The third hypothesis concerns the provision of arguments pro and contra the proposed policy change. Receiving these arguments may alert respondents to the fact that there are several sides to the issue. Their own opinions and those of others they know as well as the arguments on which these opinions are based are unlikely to be the full story. Learning about different arguments and being invited to think about them carefully may reduce the sample selection bias that may result from selective exposure and availability. This motivates the following.

\section{Hypothesis 3.}

$\mathrm{H}_{0}$ : The provision of arguments does not affect the consensus effect. $\mathrm{H}_{1}$ : The provision of arguments weakens the consensus effect.

Obviously, the three explanations underlying hypotheses 1-3 (object construal, motivation, selective exposure) are not mutually exclusive. It may even be the case that they are complementary and reinforce one another.

Finally, it has been argued that the strength of a (false) consensus effect may depend on the importance of the item under consideration (Crano (1983), Campbell (1986), Marks and Miller (1987)). In the literature there exist two competing predictions with regard to the effects of topic relevance on the consensus effect. On the one hand, Crano (1983) reports that subjects give higher consensus estimates for opinions on topics in which they have a vested interest. Campbell (1986), on the other hand, finds that topic relevance is associated with weaker consensus effects. The last hypothesis aims to contribute to these arguments:

\section{Hypothesis 4.}

$\mathrm{H}_{0}$ : Topic relevance does not affect the consensus effect.

$\mathrm{H}_{1}$ : Topic relevance affects the consensus effect. 
When testing Hypothesis 4 we will use house ownership as a proxy for topic relevance, because obviously house owners are more closely involved in maintaining mortgage deductibility than tenants.

In the next section we will first present an analysis of people's opinions about changes in the tax deductibility of the interest on mortgages. This is a hotly debated policy issue, and our data can illuminate people's stands on the topic. Thereafter, section 4 will be devoted to an analysis of the consensus effect and a test of the hypotheses put forward above. In what follows we will indicate the answer to Question A1 or A2 by 'Opinion' and the answer to Question $\mathrm{C} 1$ or C2 by 'Estimate'.

\section{OPINIONS ON THE TAX DEDUCTIBILITY OF MORTGAGES}

Averaged over all treatments we find that the average grade given to a restriction of the tax deductibility is 5.28 on a scale of 1 to 10 , which can be considered as only weak support for such a restriction. A proposal to restrict the deductibility meets with much more support, however, if it applies to mortgages as of 180000 Euro. The average Opinion in the Specific scenario is 5.70, and almost one point higher than the average Opinion in the Ambiguous scenario (4.88). The difference between the two grades is significant at the $1 \%$ level. ${ }^{5}$ A small majority (56.7\%) give a grade of 5 or less in the Ambiguous scenario, whereas in the Specific scenario a majority $(55 \%)$ give a grade of 6 or more. ${ }^{6}$ The difference is as expected since compared to the current situation in the Netherlands the specific scenario is a more moderate (less extreme) proposal as it affects only higher mortgages rather than all mortgages.

Because the tax deductibility is highly debated among politicians, it is interesting to see how people's views vary with their political orientation. Table 2 indicates how Opinion varies with the political party they intend to vote for in the next election (which was the 2002 election at the time). Roughly speaking, the support for a restriction decreases if we move from left to right in the political spectrum. Respondents that intend to vote for the SP (socialist) are most in favour of a restriction, but also amongst CU (social-christian) and GL (green party) voters many people seem to support the proposal. Most resistance can be found among people who vote for VVD (conservative), followed closely by CDA voters (christian democratic). The

5 Unless mentioned otherwise, all tests are two-sided non-parametric Mann-Whitney $U$-tests.

6 Out of the total sample (including "I don't know" responses), we find that $42.6 \%$ give a grade of 6 to the proposal for restriction. This is roughly in line with a recent questionnaire conducted by research bureau OTB / Intomart by order of Vereniging Eigen Huis in April 2006 in which it was found that in total about 45\% of the respondents believe that the deductibility should be completely abolished or restricted (see http://renteaftrek.eigenhuis.nl/Default.aspx?tabid = 147). 
TABLE 2 - AVERAGE OPINION BY POLITICAL PREFERENCE

\begin{tabular}{|c|c|c|c|c|}
\hline Political preference ${ }^{\mathrm{a}}$ & $\begin{array}{l}\text { Orientation } \\
\text { of the politi- } \\
\text { cal party }\end{array}$ & \# Respondents & $\begin{array}{l}\text { Opinion A1 } \\
\text { Ambiguous }^{\mathrm{c}}\end{array}$ & $\begin{array}{l}\text { Opinion A2 } \\
\text { Specific }^{\mathrm{c}}\end{array}$ \\
\hline $\begin{array}{l}\text { PvdA = Partij van de } \\
\text { Arbeid }\end{array}$ & $\begin{array}{l}\text { social-demo- } \\
\text { cratic }\end{array}$ & 189 & $5.07(2.86)$ & $6.01(2.85)$ \\
\hline $\begin{array}{l}\text { VVD = Volkspartij } \\
\text { voor Vrijheid en } \\
\text { Democratie }\end{array}$ & conservative & 223 & $4.35(2.66)$ & $4.75(3.12)$ \\
\hline $\begin{array}{l}\text { CDA = Christen- } \\
\text { Democratisch Appèl }\end{array}$ & $\begin{array}{l}\text { christian- } \\
\text { democratic }\end{array}$ & 177 & $4.74(2.72)$ & $5.36(2.46)$ \\
\hline $\begin{array}{l}\text { D66 = Democraten } \\
66\end{array}$ & $\begin{array}{l}\text { left-wing } \\
\text { liberal }\end{array}$ & 84 & $5.40(3.00)$ & $5.68(2.72)$ \\
\hline $\mathrm{GL}=$ Groen Links & green party & 113 & $5.50(2.87)$ & $6.51(2.48)$ \\
\hline $\begin{array}{l}\mathrm{SP}=\text { Socialistische } \\
\text { Partij }\end{array}$ & $\begin{array}{l}\text { left-wing } \\
\text { socialist }\end{array}$ & 72 & $5.87(3.35)$ & $7.06(3.03)$ \\
\hline $\mathrm{CU}=$ Christen Unie & $\begin{array}{l}\text { social-chris- } \\
\text { tian }\end{array}$ & 42 & $5.75(3.45)$ & $6.14(2.42)$ \\
\hline $\begin{array}{l}\mathrm{LN}=\text { Leefbaar } \\
\text { Nederland }\end{array}$ & $\begin{array}{l}\text { right-wing } \\
\text { liberal }\end{array}$ & 99 & $4.76(3.14)$ & $6.59(2.95)$ \\
\hline Don't know yet & & 227 & $4.71(2.91)$ & $5.29(2.77)$ \\
\hline Won't vote & & 46 & $4.45(3.43)$ & $6.58(2.64)$ \\
\hline Total & & 1283 & $4.88(2.93)$ & $5.70(2.88)$ \\
\hline
\end{tabular}

Notes: ${ }^{\text {a }}$ The list of political preferences is exclusive of SGP (preferred by 10) and Seniorenpartij (preferred by 1).

${ }^{\mathrm{b}}$ At the time the survey was conducted, this party was still led by Pim Fortuyn. He started a new party $(\mathrm{LPF}=$ Lijst Pim Fortuyn) a few months later.

${ }^{\mathrm{c}}$ Standard deviations of Opinion are in parentheses.

Specific proposal is considered to be fairer than the Ambiguous proposal, and this holds irrespective of one's political preference. ${ }^{7}$

Table 2 classifies respondents on the basis of their political preference, but it is likely that other personal characteristics affect their attitude as well. A clear variable of interest is house ownership. As could be expected tenants judge the restrictions as fairer than house owners do. Interestingly, the difference between tenants and house owners is much larger for the Ambiguous scenario (5.94 vs. 4.45$)$ than for the Specific scenario (6.10 vs. 5.57). The different views of tenants and house owners are illustrated in Figure 1 which

7 That fairness is a serious concern is also reflected in the scores that people assign to the different arguments. The argument with the highest score is that "A restriction will bring many household in financial troubles", closely followed by the argument that "House owners with a high income benefit more from deductibility than those with a low income". 

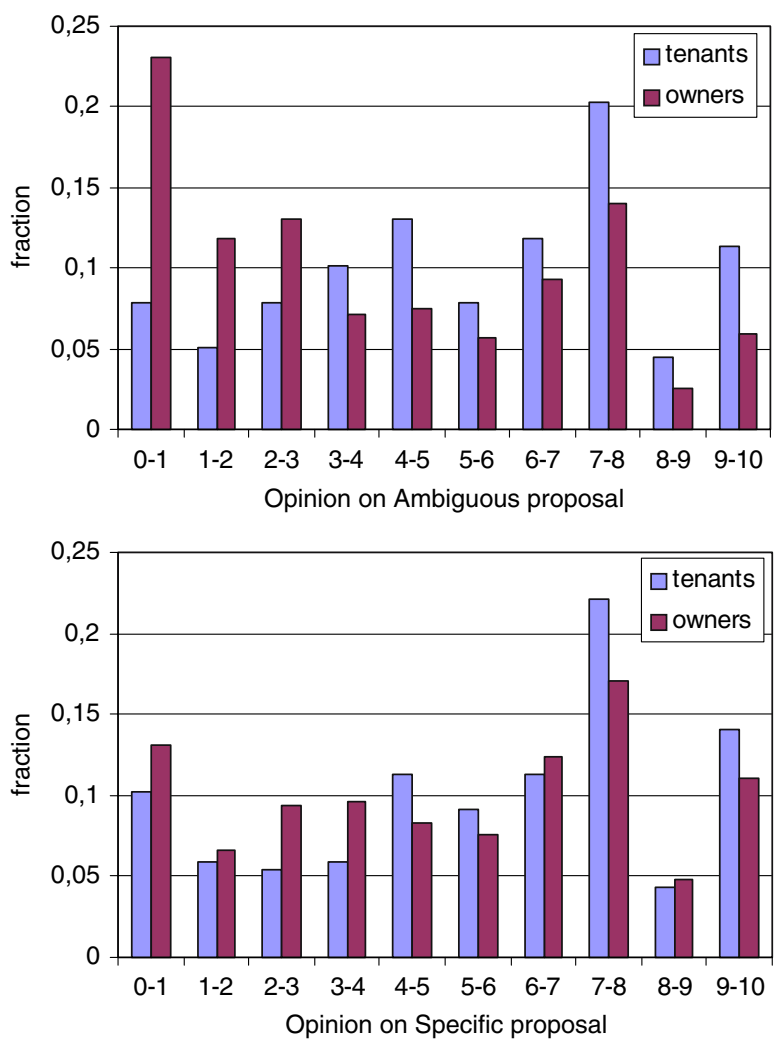

Figure 1 - Frequency distribution of opinions by tenants and house owners for Ambiguous (upper panel) and Specific (lower panel) proposal

shows the distribution of Opinions of both groups for the two scenarios separately. It can be seen that a large fraction of house owners considers the Ambiguous scenario as extremely unfair (grade 0 or 1 ), while this fraction is much smaller for the Specific scenario. Overall, the distinction between owners and tenants is smaller in the Specific scenario.

When we consider the impact of other socio-demographic characteristics in a systematic way by running a simple OLS regression (not reported here in full) it turns out that the proposal receives more support from older, higher educated, and lower-income persons, in the sense that the coefficients of these variables are significantly different from zero. Other background variables (sex, family composition, and religious orientation) appear to have little systematic relationship with the opinion on the mortgage deductibility. This suggests that people make their judgments largely in line with their self-interest. 
We also asked people whether they expected that the mortgage deductibility would be restricted in the future. Remarkably, we find that a majority (58\%) anticipate a restriction. Furthermore, this percentage is significantly higher among tenants $(69 \%)$ than among house owners (54\%). This difference could be interpreted as wishful thinking. Another possibility is that house owners know more house owners and tenants know more tenants and that this causes a bias in expectations concerning the political support for a restriction (much in line with a consensus effect).

Finally, we would like to mention that for the Ambiguous scenario the average Estimate (i.e. the answer to the question about the average grade of the panel members, $\mathrm{C} 1$ or $\mathrm{C} 2$ ) is almost identical to the average Opinion (4.87 vs. 4.88$)$ whereas in the Specific scenario the former is almost 0.5 lower $(5.26$ vs. 5.70). On average, people seem to underestimate the degree of support for a restriction of the tax deductibility if this restriction applies only to mortgages above a certain lower bound. This suggests that people's own opinions are strongly affected by redistributional considerations but that they underestimate the degree to which others' opinions are.

In summary, we find that opinions vary quite predictably with political preferences and with personal circumstances and with house ownership in particular. At the same time, opinions seem to converge considerably if the tax deductibility is restricted only for mortgages as of a certain size.

\section{THE CONSENSUS EFFECT}

In this section we will examine the presence of a consensus effect and analyze how it varies with the treatment variables of our design and with the socioeconomic background variables of the respondents. For that purpose we will relate people's own opinion to their estimate about other people's opinion.

First, Table 3 presents for each treatment separately the average values of Opinion (fourth column) and Estimate (fifth column), as well as the correlation between Opinion and Estimate (sixth column). We can see that in all but two treatments, the correlation coefficients are between 0.34 and 0.55 and they are statistically significant at the $1 \%$ level. They are highest when respondents receive no arguments (Arguments $=$ No) and are not paid for accuracy $($ Paid $=$ No), whereas the correlation coefficients drop considerably when both arguments and monetary incentives are provided. The correlation is even insignificant in the Ambiguous treatment. This suggests that the size of the consensus effect is affected by both cognitive and motivational factors and that a combination of information and monetary incentives reduces the effect.

In order to test the hypotheses more formally we first perform OLS regressions in which we take Estimate as the dependent variable. Opinion is included as an explanatory variable, and we take the estimated coefficient for Opinion as a measure for the consensus effect. We also include dummy 
TABLE 3 - AVERAGE OPINION, AVERAGE ESTIMATE, AND THE CORRELATIONS BETWEEN THEM

\begin{tabular}{llllll}
\hline Scenario & Arguments & Paid & Opinion & Estimate & Correlation \\
\hline Ambiguous & No & No & $4.95(2.90)$ & $4.67(1.93)$ & $0.544 * * *$ \\
Ambiguous & Yes & No & $4.69(2.96)$ & $4.99(2.02)$ & $0.421 * * *$ \\
Ambiguous & No & Yes & $4.87(2.93)$ & $4.85(2.17)$ & $0.452 * * *$ \\
Ambiguous & Yes & Yes & $4.91(2.98)$ & $5.27(2.23)$ & 0.122 \\
Ambiguous & & & $4.88(2.93)$ & $4.87(2.09)$ & $0.419 * * *$ \\
Specific & No & No & $5.77(2.89)$ & $5.09(1.96)$ & $0.422 * * *$ \\
Specific & Yes & No & $5.57(2.77)$ & $5.29(1.94)$ & $0.354 * * *$ \\
Specific & No & Yes & $5.77(2.91)$ & $5.34(1.97)$ & $0.343 * * *$ \\
Specific & Yes & Yes & $5.60(2.97)$ & $5.31(2.19)$ & $0.209 * *$ \\
Specific & & & $5.70(2.88)$ & $5.26(1.99)$ & $0.351 * * *$ \\
\hline
\end{tabular}

Notes: Standard deviation between parentheses. Reported correlation is Spearman's $\rho$, whereby *** indicates significant at $0.01,{ }^{* *}$ significant at $0.05,{ }^{*}$ significant at 0.10

variables for the three treatments, and first and higher order interaction terms between Opinion and the three treatment dummies. These interaction terms allow us to test whether any of the treatment variables strengthens or weakens the consensus effect, either separately or in combination.

To test the effect of background variables, and in particular their possible impact on the consensus effect, we add these variables (which are all transformed into binary variables) to the model. This results in the following specification: ${ }^{8}$

$$
\begin{aligned}
& \text { Estimate }=\alpha+\beta \text { Opinion }+\sum_{j=1}^{3} \gamma_{j} T_{j}+\sum_{j=1}^{3} \delta_{j} T_{j} \times \text { Opinion } \\
& +\sum_{j=1}^{2} \sum_{k=j+1}^{3} \eta_{j k} T_{j} \times T_{k} \times \text { Opinion }+\theta T_{1} \times T_{2} \times T_{3} \times \text { Opinion }+\lambda^{\prime} Z \\
& +\mu^{\prime} Z \times \text { Opinion }+\varepsilon
\end{aligned}
$$

where $\alpha, \beta, \gamma_{j}, \delta_{j}, \eta_{j k}$, and $\theta$, are coefficients, $\lambda$ and $\mu$ are vectors of coefficients, Estimate is a respondent's estimate of the average Opinion, Opinion is a respondent's own opinion on restricting the tax provision, $T_{1}=$ Specific, $T_{2}=$ Paid, $T_{3}=$ Arguments are the treatment dummies. Furthermore, $Z$ is a vector of seven dummy variables, which take on a value of one, respectively, if a respondent (a) is tenant, (b) is relatively poor, i.e. has a net household income

8 As the dependent variable Estimate takes values in the range $[0,10]$ a transformation may seem appropriate. However, using log ((Estimate/(10-Estimate)) does not yield better or different results, whereas the error term when using Estimate appears to follow a normal distribution too. We therefore use the standard specification, which is easier to interpret. 
TABLE 4 - REGRESSION RESULTS FOR ESTIMATE

\begin{tabular}{|c|c|c|c|c|}
\hline & $\begin{array}{l}\text { OLS } \\
\text { coeff }\end{array}$ & $p$-value & $\begin{array}{l}2 \text { SLS } \\
\text { coeff }\end{array}$ & $p$-value \\
\hline Intercept & 3.127 & 0.000 & 1.829 & 0.004 \\
\hline Opinion & 0.339 & 0.000 & 0.559 & 0.000 \\
\hline Paid & 0.371 & 0.002 & 0.298 & 0.033 \\
\hline Arguments & 0.604 & 0.000 & 0.457 & 0.009 \\
\hline Opinion $\times$ Paid $\times$ Arg & -0.099 & 0.003 & -0.036 & 0.449 \\
\hline Tenant & 0.616 & 0.030 & 1.273 & 0.227 \\
\hline Opinion $\times$ Tenant & -0.116 & 0.009 & -0.210 & 0.286 \\
\hline Poor & 0.599 & 0.009 & 1.700 & 0.054 \\
\hline Opinion $\times$ Poor & -0.070 & 0.066 & -0.259 & 0.121 \\
\hline Educate & -0.381 & 0.001 & -0.272 & 0.024 \\
\hline Children & -0.273 & 0.016 & -0.232 & 0.064 \\
\hline$R^{2}$ & 0.177 & & 0.043 & \\
\hline
\end{tabular}

Notes: The number of observations is 1224 . In the 2SLS regression, we have used the prediction for Opinion rather than the value of Opinion, which was obtained by regressing Opinion on dummy variables for political preference, age categories and gender.

below the median value in the sample ( $<€ 2045$ per month), (c) has a college education or higher, (d) is a student, (e) is married or cohabiting (f) has children, or $(\mathrm{g})$ is religious.

We first estimated the complete model, that is, with all 26 independent variables. In this model, 16 of the estimated coefficient turn out to be statistically insignificantly different from zero at the 10 percent level. In order to correct for possible specification error, we next used a backward elimination procedure in which in each step the variable with the smallest partial correlation with the dependent variable is removed. This procedure ends with all remaining variables having estimated coefficients that are significantly different from zero at least at the 10 percent level. The OLS estimation results for the model that remains after this procedure can be found in columns 2 and 3 of Table 4 (columns 4 and 5 are discussed below).

Note first that the regression results verify the existence of a clear consensus effect: the estimated coefficient $\beta$ is positive, 0.339 , and statistically significant $(p<0.001)$. The coefficient can be interpreted as the average size of the consensus effect in the Ambiguous treatment, without Arguments and Paid, i.e. when all treatment and demographic dummies are equal to zero.

Next we see that the treatment dummies for Arguments and Paid have a statistically significant positive effect on Estimate. ${ }^{9}$ If people are provided with arguments pro and contra a policy chance, they tend to give higher esti-

9 Recall from the design (Table 1) that the treatments Arguments and Paid may affect the Estimates (questions $\mathrm{C} 1$ and $\mathrm{C} 2$ ) but not the Opinions (questions A1 and A2). Mann-Whitney 
mates, which suggests that on balance the arguments in favour are considered stronger. The provision of incentives for accuracy also tends to produce higher estimates. Both of these, however, are direct effects on Estimates (i.e., not mediated by Opinion) and hence they have no bearing on the consensus effect.

The impact of the treatments on the consensus effect is measured by the interactions between the treatment dummies and Opinion. Here it turns out that the first order interactions between Opinion and the treatment dummies yield estimated coefficients $\left(\delta_{j}\right)$ that are not significantly different from zero (and always smaller than 0.04 in absolute size). Of the three second order interactions only the coefficient $\left(\eta_{23}\right)$ for Paid $\times$ Argument $\times$ Opinion is significantly different from zero. This effect was already suggested by an analysis of the correlation coefficients in Table 3 . The negative coefficient indicates that the consensus effect is reduced if subjects are provided both with arguments pro and contra and with incentives to provide accurate estimates. Moreover, this effect is substantial $(-0.099)$; reducing the consensus effect by almost $30 \%$. The other second order interaction terms are not statistically significantly different from zero and small in size. ${ }^{10}$

Of the background variables $(Z)$, in particular the distinction between tenants and house owners proves relevant. House owners not only judge the proposal as less fair than tenants do, they also think that other people give a lower grade. The interaction effect between tenants and Opinion is relatively large and negative (and significantly so) indicating that on average tenants submit Estimates that are less closely related to their own Opinion than do house owners.

Furthermore, people with an income below the median give a significantly higher estimate, which is to be expected in view of the redistributional consequences of the proposed policy. The interaction effect with Opinion is considerable in size and negative, suggesting that relatively poor people are less affected by the consensus effect. Having children and having a college education or higher also induces lower Estimates but the interaction with Opinion is not statistically (or economically) different from zero. The other background variables (religion, marital status, education, student) yield small and statistically insignificant estimates and seem to have at most a minor effect on the size of the consensus effect.

Relating these results to the hypotheses it appears that Specificity has no significant effect on the size of the consensus effect. The null-version of Hypothesis 1 cannot be rejected. The same holds for Hypothesis 2 and Hypothesis 3, meaning that the provision of monetary incentives and the pro-

$\mathrm{U}$ test reveal indeed no significant difference across the Paid/Not Paid treatment and the Arguments/No Arguments treatment for Opinion.

10 The result of a $F$-test indicates that we cannot reject the hypothesis that the coefficients of the seven Opinion-treatment interaction terms $\left(\delta_{j}, \eta_{j k}, \theta\right)$ are jointly equal to zero $(p=0.12)$. 
vision of arguments pro and contra do not reduce the consensus effect, if considered in isolation. The significant effect of the interaction term for Paid $x$ Argument $\times$ Opinion, however, shows that in combination the provision of incentives and arguments do reduce the consensus effect. This suggests that both motivational and cognitive factors play a role. The (strong) effect of ownership is in line with Crano's findings that subjects give higher consensus estimates on issues in which they have a vested interest (Crano (1983)), meaning that we can reject the $\mathrm{H}_{0}$ version of Hypothesis 4 in favour of $\mathrm{H}_{1}$.

Finally, we perform a robustness check on the results of the OLS estimation results. This model assumes that Opinion is an exogenous variable, while one could argue that actually both Estimate and Opinion are endogenous variables. ${ }^{11}$ Therefore, we estimated a second model (2SLS), which takes this into account, by not including Opinion directly, but replacing it by an instrumental variable which is independent of the error term in the original specification. ${ }^{12}$ For the model we use the exact same specification as the OLS model reported in Table 4. The results reveal that the estimated coefficient for the consensus effect is still statistically significant if we take an instrument for Opinion and the size of the effect even increases substantially. Also the signs and sizes of most of the other estimated coefficients match those of the OLS model very well, even though some of the effects lose statistical significance. Overall, however, we can say that the results are fairly robust.

\section{RESULTS ON ACCURACY AND INCENTIVE EFFECTS}

In this section we present some additional results on the accuracy of the estimates and on incentive effects.

\subsection{Accuracy}

For each respondent we have computed the error as the absolute value of the difference between the Estimate and the mean value of Opinion in the relevant scenario (Specific or Ambiguous). Columns 3 and 4 in Table 5 show the mean errors by treatment for all respondents (the last four columns will be discussed later).

From the table we can infer that the mean errors are not much affected by the treatment variables. Whether or not Arguments are provided before the Estimate does not have any effect on the average error. Remarkably, paying the subjects for making accurate estimates does not make errors smaller. In

11 We thank a referee for pointing this out to us.

12 Just as in Harmon et al. (2003) for example, when constructing an instrument for Opinion we only use variables that affect Opinion (see section 3) and at the same time are likely to be exogenous to Estimate (namely dummy variables for political preference, age categories and gender). These variables are omitted from the model for Estimate. 
TABLE 5 - MEAN ABSOLUTE ERRORS BY TREATMENT

\begin{tabular}{|c|c|c|c|c|c|c|c|}
\hline \multirow[t]{2}{*}{ Scenario } & \multirow[t]{2}{*}{ Arguments } & \multicolumn{2}{|c|}{ All respondents } & \multicolumn{2}{|l|}{ Owners } & \multicolumn{2}{|l|}{ Tenants } \\
\hline & & Not Paid & Paid & Not Paid & Paid & Not Paid & Paid \\
\hline Ambiguous & No & 1.59 & 1.89 & 1.63 & 1.88 & 1.47 & 1.89 \\
\hline Ambiguous & Yes & 1.66 & 1.99 & 1.72 & 2.00 & 1.51 & 1.93 \\
\hline Specific & No & 1.65 & 1.70 & 1.70 & 1.79 & 1.53 & 1.50 \\
\hline \multirow[t]{2}{*}{ Specific } & Yes & 1.54 & 1.89 & 1.48 & 1.97 & 1.70 & 1.74 \\
\hline & Total & 1.60 & 1.83 & 1.63 & 1.88 & 1.54 & 1.71 \\
\hline
\end{tabular}

fact, errors are larger in the Paid treatment, and this is the only effect that is statistically significant if we run a simple OLS regression with the absolute error as the dependent variable and dummies for the treatment variables as explanatory variables.

Marks and Miller (1987) and Campbell (1986) argued that the accuracy of estimations increases as opinion relevance (i.e. personal importance of the issue) increases. Applied to our situation this suggests that house owners make more accurate estimates. The mean errors by treatment for house owners and tenants separately, as shown in the last four columns of Table 4 do not lend support to the claim: if anything, house owners make less accurate estimates than tenants. Indeed, if we extend the above-mentioned analysis with the absolute error as dependent variable by adding ownership as explanatory variable in addition to dummies for the treatment variables, it turns out that the estimated coefficient for owner is significantly positive, as it is for Paid. ${ }^{13}$

\subsection{Incentive Effect}

The analyses in the previous sections suggest that paying or not paying the subjects does not have a very strong effect on the size of the consensus effect, and that an effect is likely to occur mainly if Arguments are provided as well. Does this imply that there is hardly any incentive effect at all? When we look more closely at the answers, some remarkable differences between the Paid and the Not Paid treatment can be observed.

First, the fraction of "I don't know" answers to the estimation question is considerably lower in the payment treatment $(8.5 \%)$ than in no-payment treatment $(17.3 \%)$. This, of course, makes sense. Even if people really have no clue, they still have an incentive to submit an Estimate in order to be eligible for the 100 Euro in the Paid treatment.

13 Campbell (1986) also suggested that respondents might be less biased and more accurate on issues that are relevant to them because they would be better informed about these issues. This argument suggests an interaction effect between information and ownership, but we do not find support for this. 
Moreover, the number of people who chose a prominent number (i.e. x.00 or x.50) is clearly affected by monetary incentives. The fraction of subjects submitting such numbers is $74.9 \%(n=729)$ in the Not Paid treatment, but only $24.4 \%(n=804)$ in the Paid treatment. So although payment does not lead to substantial qualitative differences, it seems to affect people and to motivate them to make other (but not more precise) estimates. If we perform a logistic regression with Prominence (being 1 if a prominent number has been given and 0 otherwise) as the dependent variable, and the treatment variables, socio-economic variables, and interaction terms between the socio-economic variables and the Paid treatment variable as the independent variables, it turns out that Paid is a highly significant variable, reducing the number of prominent estimates. The other two treatment variables have coefficients that are not significantly different from zero. (And why would they?) From the interaction effects with Paid we can infer that younger, male and more educated respondents are more strongly affected by the Paid treatment, giving fewer prominent estimates when paid for making accurate estimates.

\section{CONCLUSIONS}

Our study started from the observation in the social psychological literature that expectations about the behaviour and preferences of others are positively correlated with one's own behaviour and preferences. This consensus effect may have important implications for economics. In this paper we have considered the role of the consensus effect in relationship to an issue that has been under much debate in the Netherlands, namely the proposal to restrict the tax deductibility of interest payments on mortgages.

Concerning the restriction of the tax deductibility it appears that a small majority of the 1454 Dutch respondents consider the proposal to restrict the mortgage interest deductibility when no upper limit is set to be unfair (i.e. they gave a grade of at most a 5) whereas a small majority consider the proposal to restrict the interest deductibility for mortgages above a certain size to be fair (i.e. they gave at least a 6). The proposal is received more positively among left wing voters (SP, Groen Links) than among right wing voters (CDA, VVD), and more positively among tenants than house owners. Also people with incomes below the median, those with relatively high education, and those above a certain age tend to be more positive toward a restriction.

We found clear indications for the existence of a consensus effect in our experiment i.e. respondents estimates of others' opinions are strongly related to their own opinion. We examined the effect of three treatment variables that were each motivated by one of the possible causes of the consensus effect. One of the treatments was the Specificity of the policy proposal, a variable that was motivated by the possible impact of object construal. We found no evidence that it affected the size of the consensus effect. We did find a small 
effect of the other two treatments: the provision of Arguments pro and contra the proposal, and the presence of monetary incentive to give an accurate estimate about others' opinions. In particular, the results show that these two treatment variables may be complementary. If this is the case it suggests that in order to reduce the consensus effect both the effect of selective exposure (sample selection bias) and motivational factors have to be overcome. This complements Engelmann and Strobel's (2000) finding that a false consensus effect only disappears if information about other people is presented to subjects on a silver platter, such that no cognitive effort is needed to use relevant information.

Among the socio-demographic variables by far the most important one was house ownership. House owners indicated a much lower support for the policy proposal. More interesting is that they also displayed a much stronger consensus effect. As house owners have a strong vested interest in the tax regime toward mortgages this suggests that topic relevance tends to strengthen the consensus effect.

The results may help explain why the tax deductibility of mortgage interests is such a sensitive issue in (Dutch) politics, considered to be best left untouched by politicians. Not only do vested interests and opinions differ widely among the population, due to the consensus effect people also tend to regard their own opinions as representative for those of others. As a result they will have little understanding for the fact that others have a different opinion. This widens the gap between the proponents and the opponents of a policy change, and hampers the prospects for compromise and consensus. Our results suggest that in order to facilitate a policy change, it is best to propose a restriction of the deductibility only for mortgages as of a certain size. This increases the support across the board, but it also narrows the opinion differences between tenants and house-owners. Moreover, when people are actively encouraged to take notice of the arguments of both sides they seem to better appreciate the fact that others have a different opinion. This may also make a policy change easier.

Our findings suggest that the consensus effect may also be relevant for economic settings in which people have an incentive to be as accurate as possible about the behaviour or preferences of others. Think for example of people considering starting a business and having to estimate market demand while knowing their own preferences. If a consensus effect were due to motivational factors only one might expect it to disappear when there is enough at stake. However, cognitive limitations will not always be counteracted merely by means of incentives. In particular, in order to reduce the force of selective exposure and availability (sample selection bias) it is likely that people need to be exposed to debiasing information about the preferences and beliefs of others and need to be motivated to use this information. 


\section{REFERENCES}

Brosig, J., Weimann, J. and C.-L. Yang (2003), 'The Hot Versus Cold Effect in a Simple Bargaining Experiment,' Experimental Economics, 6, pp. 75-90.

Brown, C.E. (1982), 'A false consensus in 1980 Presidential Preferences,' Journal of Social Psychology, 118, pp. 137-138.

Camerer, C. (1995), 'Individual Decision Making, in: J. Kagel and A. Roth (eds.), Handbook of Experimental Economics, Princeton, Princeton University Press.

Campbell, J.D. (1986), 'Similarity and Uniqueness: The Effects of Attribute Type, Relevance, and Individual Differences in Self-esteem and Depression,' Journal of Personality and Social Psychology, 50, pp. 281-294.

Charness, G. and B. Grosskopf (2001), 'Relative Payoffs and Happiness: an Experimental Study,' Journal of Economic Behavior and Organization, 45, pp. 301-328.

Crano, W.D. (1983), 'Assumed Consensus of Attitudes: The Effect of Vested Interest,' Personality and Social Psychology Bulletin, 9, pp. 597-606.

Dawes, R.M. (1990), 'The Potential Nonfalsity of the False Consensus Effect,' in: R. Hogarth (ed.), Insight in Decision Making. A Tribute to Hillel J. Einhorn, Chicago, Chicago University Press.

Engelmann, D. and M. Strobel (2000), 'The False Consensus Effect Disappears if Representative Information and Monetary Incentives are Given,' Experimental Economics, 3, pp. 241260.

Engelmann, D. and M. Strobel (2004), 'The False Consensus Effect: Deconstruction and Reconstruction of an Anomaly,' mimeo, CERGE-EI, Charles University, Prague.

Forsythe, R., F. Nelson, G.R. Neumann, and J. Wright (1992), 'Anatomy of an Experimental Political Stock Market,' American Economic Review, 82, pp. 1142-1161.

Goethals, G.R., S.J. Allison, and M. Frost (1979), 'Perceptions of the Magnitude and Diversity of Social Support,' Journal of Experimental Social Psychology, 15, pp. 570-581.

Harmon, C., H. Oosterbeek, and I. Walker (2003) 'The Returns to Education: microeconomics,' Journal of Economic Surveys, 17, pp. 115-155.

Jacobsen, E. and Sadrieh (1996), 'Experimental Proof for the Motivational Importance of Reciprocity,' University of Bonn, Discussion Paper No. B-386.

Manstead, A.S.R. (1982), 'Perceived Social Support for Opinions: A test of the Magnitude and Diversity Hypotheses,' British Journal of Social Psychology 21, pp. 35-41.

Marks, G. and N. Miller (1987), 'Ten Years of Research on the False Consensus Effect: An Empirical and Theoretical Overview,' Psychological Bulletin, 102, pp.72-90.

Mullen, B. and L. Hu (1988), 'Social Projection as a Function of Cognitive Mechanisms: Two Meta-analytic Integrations,' British Journal of Social Psychology, pp. 27, 333-356.

Offerman, T., J. Sonnemans, and A. Schram (1996), 'Value Orientations, Expectations and Voluntary Contributions in Public Goods,' Economic Journal, 106, pp. 817-845.

Ross, L., D. Greene, and P. House (1977), 'The 'False Consensus Effect: An Egocentric Bias in Social Perception and Attribution Processes,' Journal of Experimental Social Psychology, 13, pp. 279-301.

Selten, R. and A. Ockenfels (1998), 'An Experimental Solidarity Game,' Journal of Economic Behavior and Organization, 34, pp. 517-539. 